\title{
Thermal evolution of defects in undoped zinc oxide grown by pulsed laser deposition
}

\author{
Zilan Wang, ${ }^{1}$ Shichen Su, ${ }^{1}$ Francis Chi-Chung Ling, ${ }^{1, a)}$ W. Anwand, ${ }^{2}$ and A. Wagner ${ }^{2}$ \\ ${ }^{1}$ Department of Physics, The University of Hong Kong, Pokfulam Road, Hong Kong, \\ People's Republic of China \\ ${ }^{2}$ Institute of Radiation Physics, Helmholtz-Zentrum Dresden-Rossendorf, Bautzner Landstr. 400, \\ 01328 Dresden, Germany
}

(Received 13 May 2014; accepted 5 July 2014; published online 16 July 2014)

\begin{abstract}
Undoped $\mathrm{ZnO}$ films are grown by pulsed laser deposition on c-plane sapphire with different oxygen pressures. Thermal evolutions of defects in the $\mathrm{ZnO}$ films are studied by secondary ion mass spectroscopy (SIMS), Raman spectroscopy, and positron annihilation spectroscopy (PAS), and with the electrical properties characterized by the room temperature Hall measurement. Oxygen deficient defect related Raman lines $560 \mathrm{~cm}^{-1}$ and $584 \mathrm{~cm}^{-1}$ are identified and their origins are discussed. Thermal annealing induces extensive $\mathrm{Zn}$ out-diffusion at the $\mathrm{ZnO} /$ sapphire interface and leaves out $\mathrm{Zn}$-vacancy in the $\mathrm{ZnO}$ film. Two types of $\mathrm{Zn}$-vacancy related defects with different microstructures are identified in the films. One of them dominates in the samples grown without oxygen. Annealing the sample grown without oxygen or growing the samples in oxygen would favor the Zn-vacancy with another microstructure, and this Zn-vacancy defect persists after $1100{ }^{\circ} \mathrm{C}$ annealing. (C) 2014 AIP Publishing LLC. [http://dx.doi.org/10.1063/1.4890460]
\end{abstract}

\section{INTRODUCTION}

$\mathrm{ZnO}$ has been received great deal of attention in the past 10 years because of its excellent physical properties for fabricating optoelectronic devices. ${ }^{1}$ Defects in semiconductors play crucial role in determining the materials optical and electrical properties. The realization of practical $\mathrm{ZnO}$-based devices is still suffering from the asymmetric p-type doping difficulty of $\mathrm{ZnO},{ }^{2,3}$ which is also at least partially related to the poor understandings of the defects, defect compensation, and defect control in the $\mathrm{ZnO}$ materials.

There have been theoretical studies on the defects of $\mathrm{ZnO}$ but the results are dependent on the approach, approximation, and post-process adopted (Refs. 4-7 and references therein). It is generally accepted that $\mathrm{Zn}$ vacancy is a double acceptor having energy states $\varepsilon(0 /-1)$ and $\varepsilon(-1 /-2)$ at $0.1-0.2 \mathrm{eV}$ and $0.9-1.2 \mathrm{eV}$ above the valence band, respectively. The calculated formation energy of $\mathrm{V}_{\mathrm{Zn}}$ is high in p-type $\mathrm{ZnO}$ and it decreases with the $\mathrm{E}_{\mathrm{F}}$ moving towards the conduction band. $\mathrm{V}_{\mathrm{Zn}}$ is the important residual acceptor in n-type $\mathrm{ZnO}$ material. Oxygen vacancy is generally agreed to be a deep negative $U$ donor with the state $\varepsilon(0 / 2+)$ calculated to be $0.4-0.8 \mathrm{eV}$. It has low formation energy for p-type $\mathrm{ZnO}$, but the calculation results show divergence on whether $\mathrm{V}_{\mathrm{O}}$ exists in n-type $\mathrm{ZnO}$. $\mathrm{Zn}$ interstitial is a shallow donor. It is mobile at low temperature because of its low migration barrier. The oxygen interstitial exists in two configurations namely the octahedral configuration and the tetrahedral split configuration. The octahedral configuration has two deep acceptors states, but its formation energy is high in equilibrium situation. The split configuration has lower formation energy but it is electrically inactive. Zn-antisite has the

\footnotetext{
a) Author to whom correspondence should be addressed. Electronic mail: ccling@hku.hk
}

calculated high formation energy for n-type $\mathrm{ZnO}$. The calculated formation energy for the oxygen antisite is high and is not expected to exist in equilibrium situation.

Experimental defect study of $\mathrm{ZnO}$ has been performed using a variety of spectroscopic techniques like positron annihilation spectroscopy (PAS), ${ }^{8-15}$ photoluminescence (PL), ${ }^{16-21}$ and Raman spectroscopy (RS). ${ }^{22-26}$ PAS is selectively sensitive to $V_{Z n}$ related defects. $V_{Z n}$ (Refs. 8-10) and $\mathrm{V}_{\mathrm{Zn}}$-hydrogen complexes ${ }^{12}$ have been identified in n-type $\mathrm{ZnO}$. PAS has also been used to study the different $\mathrm{Zn}$ vacancy related phenomena like the thermal induced formation and the dissociation of the shallow acceptor in As-doped $\mathrm{ZnO},{ }^{13,14}$ the residual donor responsible for the n-type conductivity in undoped $\mathrm{ZnO},{ }^{15}$ etc. Broad defect emission bands with different wavelengths are frequently observed in $\mathrm{ZnO}$ materials. Among these defect emissions with different colors, green luminescence (GL) is commonly observed but its origin is controversial. It has been ascribed to $\mathrm{Cu}$ impurity, ${ }^{16} \mathrm{Zn}$-vacancy, ${ }^{17} \mathrm{O}$-vacancy, ${ }^{18} \mathrm{O}$-antisite $\left(\mathrm{O}_{\mathrm{Zn}}\right),{ }^{20} \mathrm{Zn}$ interstitial complex, ${ }^{21}$ etc. Two Raman modes of $584 \mathrm{~cm}^{-1}$ $\left(\mathrm{E}_{1}-\mathrm{LO}\right)$ and $560 \mathrm{~cm}^{-1}$ were reported to be defect related and have been associated to O-vacancy and $\mathrm{Zn}$-interstitial, respectively. ${ }^{22-26}$

In the present study, defects in pulsed laser deposition (PLD) grown undoped $\mathrm{ZnO}$ films are investigated by a variety of spectroscopy methods, including PAS, Raman spectroscopy, and secondary ion mass spectroscopy (SIMS). The effects of growth stoichiometry and post-growth annealing are systemically studied.

\section{EXPERIMENTAL}

Undoped $\mathrm{ZnO}$ films were grown by the PLD method on the c-plane sapphire substrate. The $\mathrm{ZnO}$ target is obtained from the Kurt J. Lesker Co. (purity of 99.999\%). The 
background pressure of the growth chamber is $1 \times 10^{-4} \mathrm{~Pa}$. To study the effect of growth stoichiometry, the growth was carried out with three different oxygen pressures, namely, $\mathrm{PO}_{2}=0 \mathrm{~Pa}$, 1.3 Pa, and $5 \mathrm{~Pa}$. During the growth, $248 \mathrm{~nm}$ laser pulse from the Coherent COMPexPro 102 excimer laser was used. The pulse energy and repetition rate of the laser pulse are $300 \mathrm{~mJ}$ and $2 \mathrm{~Hz}$, respectively. The substrate temperature was kept at $300{ }^{\circ} \mathrm{C}$ during the growth. The isochronal annealing process was conducted in a tube furnace in the Ar atmosphere for $30 \mathrm{~min}$ at different annealing temperatures $\mathrm{T}_{\text {anneal }}$ up to $1100{ }^{\circ} \mathrm{C}$. For the atomic force microscopic study, the $\mathrm{ZnO}$ samples are covered with and without another piece of $\mathrm{ZnO}$ in the $\mathrm{Ar}$ atmosphere to investigate the effect on the surface roughness. For the other spectroscopic measurements, the $\mathrm{ZnO}$ samples are annealed open to the $\mathrm{Ar}$ atmosphere without cover. The Hall measurement was conducted at room temperature using the van der Pauw configuration by the Accenet HL-5500PC system. X-ray diffraction measurement was performed using the Bruker D8 Advance $\mathrm{X}$-ray diffractometer with the $\mathrm{Cu} \mathrm{K} \alpha$ line $(0.1541 \mathrm{~nm})$. The SIMS measurement was conducted using the Cameca (Model IMS 4F) dynamic secondary ion mass spectrometer. The Raman measurement was carried out using a WITecAlpha con-focal micro-Raman system under the back scattering geometric configuration. The excitation source is a $514.5 \mathrm{~nm}$ Ar laser with an output power of $30 \mathrm{~mW}$. The laser beam is focused onto the sample with a $60 \times$ objective. Atomic force microscope (AFM) measurement is carried out to investigate the morphology using the Asylum Research MFP3D in semi-contact (tapping) mode.

PAS measurement was carried out using a $25 \mathrm{keV}$ mono-energetic positron beam as the positron source. The annihilation gamma ray energy spectrum is collected using a high purity Ge detector and the corresponding nuclear electronic, which has an energy resolution of $1.3 \mathrm{keV}$ for the $514 \mathrm{keV}$ line. The Doppler broadening of the annihilation gamma photons is monitored by the $\mathrm{S}$ - and $\mathrm{W}$-parameters, which are defined as the ratios of the central window count, and the summation of the two wings count to the total count of the annihilation peak, respectively. The window for the S-parameter is $511 \pm 0.76 \mathrm{keV}$, and those for the $\mathrm{W}$-parameter are $511 \pm 3.4 \mathrm{keV}$ and $511 \pm 6.8 \mathrm{keV}$. Experimental details of the PAS measurement can be found in Ref. 13. For the case of $\mathrm{ZnO}$, the PAS parameters (i.e., the $\mathrm{S}$ and $\mathrm{W}$ parameters) are selectively sensitive to $\mathrm{V}_{\mathrm{Zn}}$ and its related complex.

\section{RESULTS AND DISCUSSIONS}

Figures 1(a) and 1(b) show the AFM images of the oxygen free grown samples in the as-grown state and after the $900{ }^{\circ} \mathrm{C}$ annealing open to $\mathrm{Ar}$ atmosphere, respectively. The surface of the $900^{\circ} \mathrm{C}$ annealed sample is damaged, but damage is not found in samples annealed at $750{ }^{\circ} \mathrm{C}$. The surface roughness of the as-grown sample is $1.97 \mathrm{~nm}$ and that after the $900{ }^{\circ} \mathrm{C}$ covered annealing increases to $3.37 \mathrm{~nm}$. With the aim to reduce the surface damage and improve the roughness, we have covered another piece of $\mathrm{ZnO}$ on top of the sample during the $900{ }^{\circ} \mathrm{C}$ annealing process and the AFM
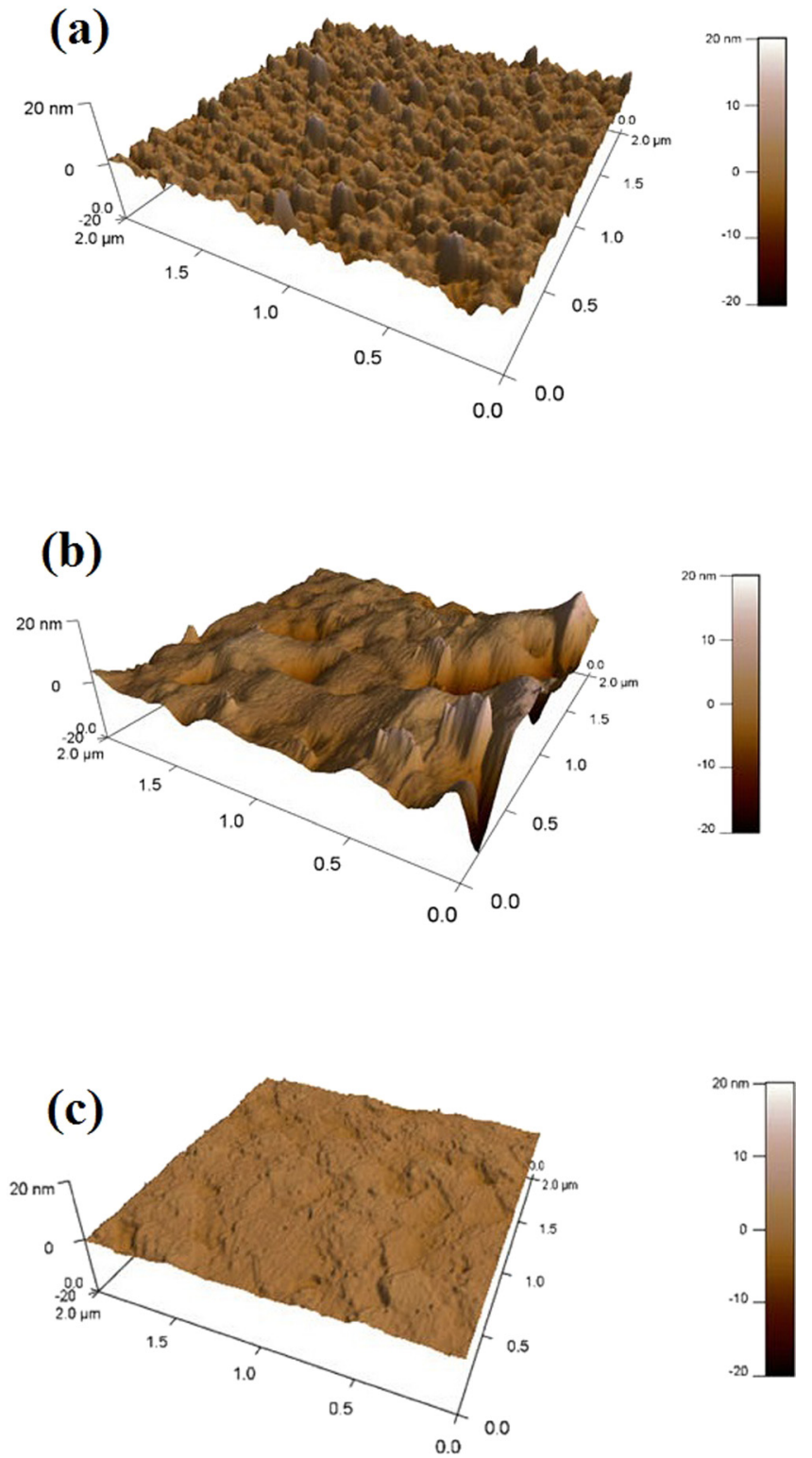

FIG. 1. AFM pictures showing the morphology of the $\mathrm{ZnO}$ samples: (a) asgrown; (b) annealed at $900^{\circ} \mathrm{C}$ with the cover of another piece of $\mathrm{ZnO}$; and (c) annealed at $900^{\circ} \mathrm{C}$ without the cover of another piece of $\mathrm{ZnO}$. The samples are grown with the oxygen pressure of $0 \mathrm{~Pa}$.

image was shown in Figure 1(c). No surface damage is found and the surface roughness reduces to $0.82 \mathrm{~nm}$.

XRD measurements have been carried out on the samples grown at the $\mathrm{PO}_{2}$ of $0 \mathrm{~Pa}$ and $5 \mathrm{~Pa}$. Three peaks are identified in all the XRD spectra, namely, peaking at $34.5^{\circ}$, $41.7^{\circ}$, and $72.1^{\circ}$ and being associated with $\mathrm{ZnO}$ (002), sapphire (006), and $\mathrm{ZnO}(004)$, respectively. Figure 2 shows the region of the XRD spectra containing the $\mathrm{Zn}$ (002) and sapphire (006) peaks for the samples grown at $\mathrm{PO}_{2}$ of $0 \mathrm{~Pa}$ and annealed at different temperature. This indicates that the grown $\mathrm{ZnO}$ film has the single-phase wurtzite structure with the c-axis as the preferential orientation. Figure 3 shows the full-width-half-maximum (FWHM) of the $\mathrm{ZnO}$ (002) peaks against the annealing temperature for the samples with $\mathrm{PO}_{2}$ equal to $0 \mathrm{~Pa}$ and $5 \mathrm{~Pa}$. The FWHM decreases with the annealing temperature, indicating the improvement of the 


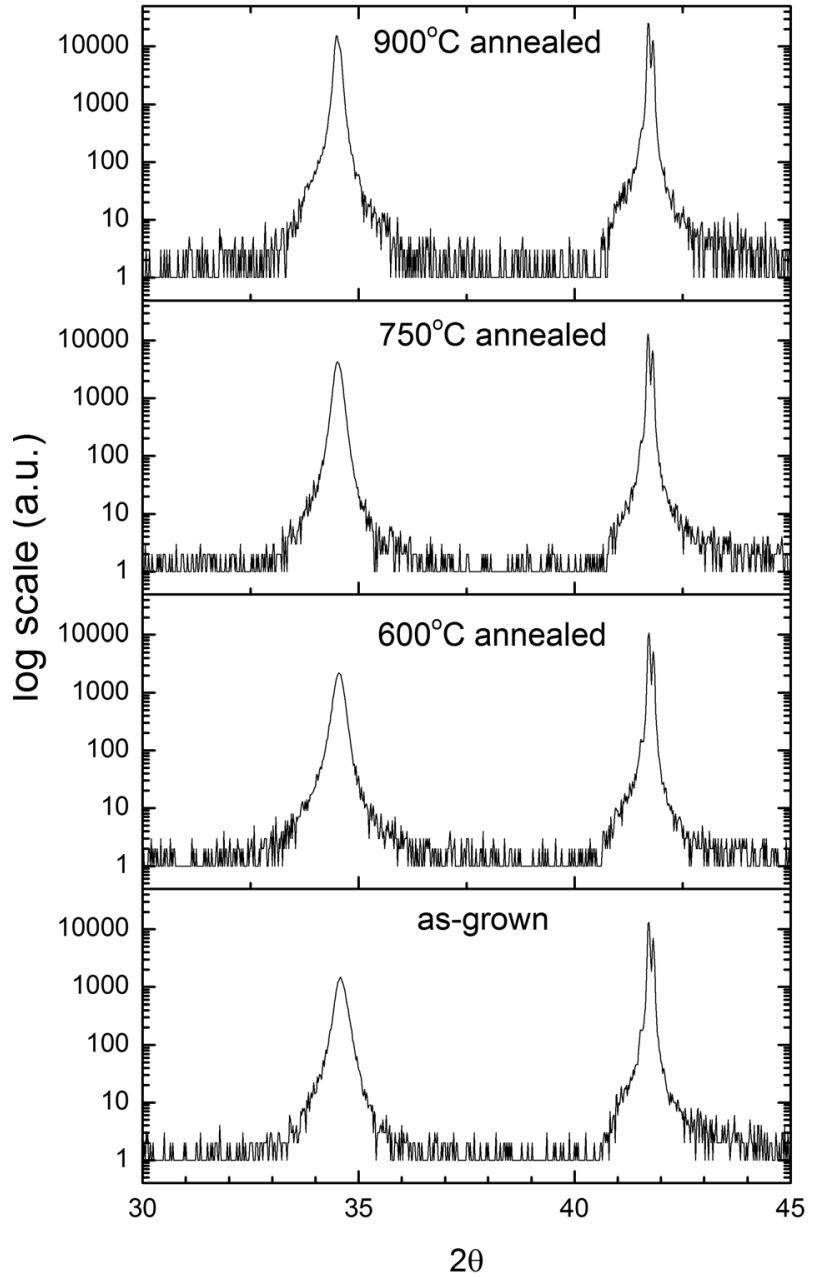

FIG. 2. The $\mathrm{ZnO}(002)$ and sapphire (600) peaks as found in the XRD spectra for the samples grown at the substrate temperature of $300{ }^{\circ} \mathrm{C}$ with $0 \mathrm{~Pa}$ oxygen pressure undergone different annealing temperatures.

crystalline quality. At the annealing temperature of $900^{\circ} \mathrm{C}$, the FWHM reaches value of $\sim 0.12^{\circ}$, irrespective of the initial growth oxygen pressure.

Figure 4 shows the electron concentrations as a function of the annealing temperature for the $\mathrm{ZnO}$ samples grown at

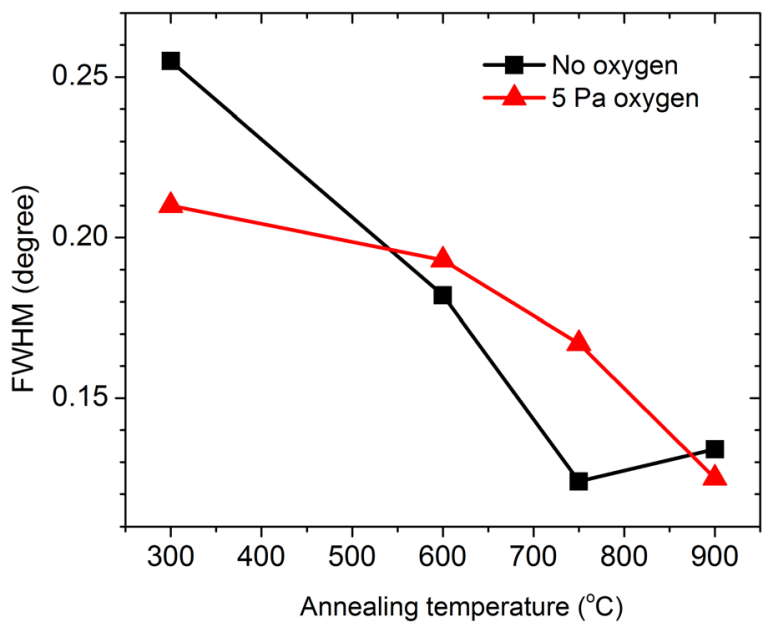

FIG. 3. The FWHM of the $\mathrm{ZnO}$ (002) peaks as a function of the annealing temperature. The samples are grown at the substrate temperature of $300^{\circ} \mathrm{C}$ in the oxygen pressures of $0 \mathrm{~Pa}$ and $5 \mathrm{~Pa}$.

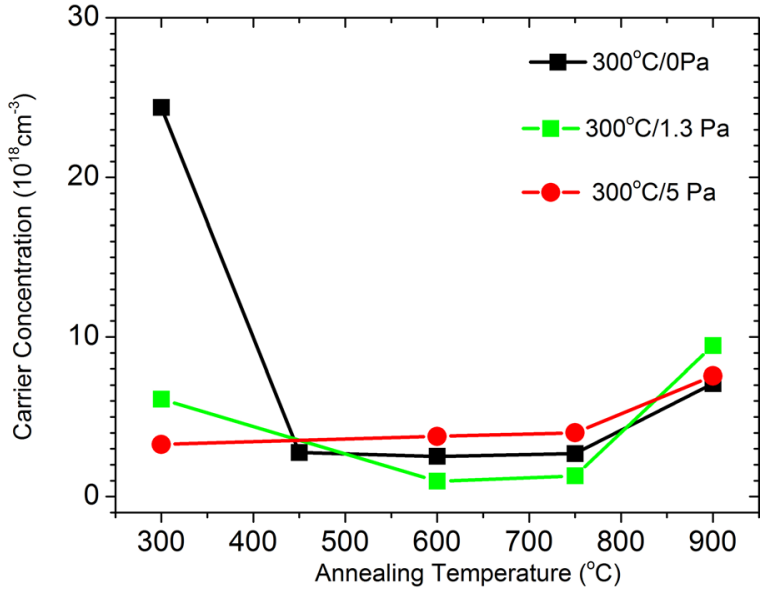

FIG. 4. The data of the electron concentration against the annealing temperature for the $\mathrm{ZnO}$ samples grown with the oxygen pressures of $0 \mathrm{~Pa}, 1.3 \mathrm{~Pa}$, and $5 \mathrm{~Pa}$.

$\mathrm{PO}_{2}$ of $0 \mathrm{~Pa}, 1.3 \mathrm{~Pa}$, and $5 \mathrm{~Pa}$. The as-grown sample grown with no oxygen has electron concentration of $2 \times 10^{19} \mathrm{~cm}^{-3}$. For the other two samples grown with oxygen, the as-grown electron concentrations are $\sim 3-6 \times 10^{18} \mathrm{~cm}^{-3}$, which are significantly lower than that grown without oxygen. Irrespective of the oxygen pressure during growth, all the three samples have electron concentrations laying in a relatively narrow range of $1-6 \times 10^{18} \mathrm{~cm}^{-3}$ for the annealing temperature range between $450{ }^{\circ} \mathrm{C}$ and $750^{\circ} \mathrm{C}$. For all the samples, further annealing up to $900^{\circ} \mathrm{C}$ would have the effect of slightly increasing the electron concentration, reaching values of $7-9 \times 10^{18} \mathrm{~cm}^{-3}$. The three as-grown samples have the mobility of $\sim 20-30 \mathrm{~cm}^{2} \mathrm{~V}^{-1} \mathrm{~s}^{-1}$ and have the maximum mobility achieved after the $900^{\circ} \mathrm{C}$ annealing with the values of 95 $\mathrm{cm}^{2} \mathrm{~V}^{-1} \mathrm{~s}^{-1}, 50 \mathrm{~cm}^{2} \mathrm{~V}^{-1} \mathrm{~s}^{-1}$, and $85 \mathrm{~cm}^{2} \mathrm{~V}^{-1} \mathrm{~s}^{-1}$ for the samples grown at $\mathrm{PO}_{2}=0,1.3$, and $5 \mathrm{~Pa}$, respectively.

To monitor for the hydrogen in the $\mathrm{ZnO}$ film as well as the $\mathrm{Zn}$ and $\mathrm{Al}$ inter-diffusion at the $\mathrm{ZnO} /$ sapphire interface, SIMS measurements were conducted on the samples grown with $\mathrm{PO}_{2}=0 \mathrm{~Pa}$ and $1.3 \mathrm{~Pa}$, and upon the post-growth annealing with different temperatures. Figures 5 and 6 , respectively, show the SIMS depth profiles of $\mathrm{Zn}, \mathrm{Al}$, and $\mathrm{H}$ for the samples grown with $\mathrm{PO}_{2}=0 \mathrm{~Pa}$ and $1.3 \mathrm{~Pa}$ annealed at different temperatures. Hydrogen is found throughout the $\mathrm{ZnO}$ film in all the samples. The $\mathrm{H}$ concentrations were calculated using a control undoped $\mathrm{ZnO}$ sample implanted by $\mathrm{H}$ with known fluence and energy, and with the SIMS signal intensity calibrated against the $\mathrm{H}$ concentration obtained by the Monte Carlo TRIM ${ }^{27}$ code. The thus calculated $\mathrm{H}$ concentrations of the PLD grown $\mathrm{ZnO}$ samples against the annealing temperature are shown in Figure 7. The as-grown sample grown at $1.3 \mathrm{~Pa}$ oxygen pressure has higher $\mathrm{H}$-concentration than that grown without oxygen $\left(2.5 \times 10^{19} \mathrm{~cm}^{-3}\right.$ and $1.2 \times 10^{19}$ $\mathrm{cm}^{-3}$, respectively). After the $600^{\circ} \mathrm{C}$ annealing, the $\mathrm{H}-$ concentrations of both sets of the samples dropped significantly to the similar value of $\sim 8 \times 10^{18} \mathrm{~cm}^{-3}$. They then decreased very slightly after the $900^{\circ} \mathrm{C}$ annealing.

For both the samples grown with $\mathrm{PO}_{2}=0$ and $1.3 \mathrm{~Pa}$, the inter-diffusions of $\mathrm{Al}$ and $\mathrm{Zn}$ across the $\mathrm{ZnO} /$ sapphire interfaces in the as-grown samples are with the depth of 


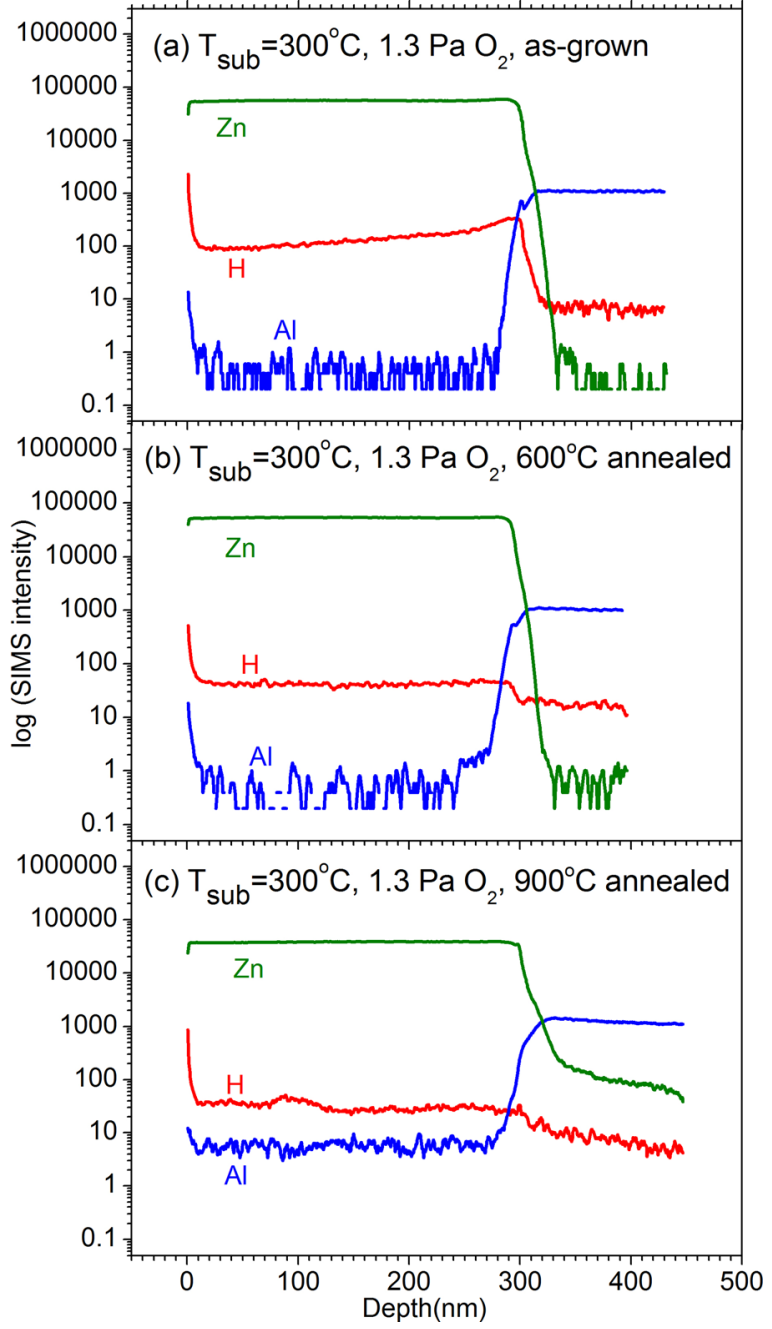

FIG. 5. The SIMS depth profiles of $\mathrm{H}, \mathrm{Zn}$, and $\mathrm{Al}$ of the (a) as-grown; (b) $600^{\circ} \mathrm{C}$ annealed; and (c) $900^{\circ} \mathrm{C}$ annealed samples grown without oxygen.

$\sim 30 \mathrm{~nm}$ (Figure 5 and 6). After the $600^{\circ} \mathrm{C}$ annealing, the inter-diffusion depths of $\mathrm{Al}$ and $\mathrm{Zn}$ slightly increase to $\sim 30-40 \mathrm{~nm}$. The $900^{\circ} \mathrm{C}$ thermal annealing induced $\mathrm{Zn}$ outdiffusion from the $\mathrm{ZnO}$ film is very different for the samples grown with and without oxygen during the growth. For the sample grown without oxygen, the $\mathrm{ZnO} /$ sapphire interface is relatively stable, with the diffusion depths of $\mathrm{Al}$ and $\mathrm{Zn}$ increased to $50 \mathrm{~nm}$ and $40 \mathrm{~nm}$, respectively, after the $900{ }^{\circ} \mathrm{C}$ annealing. However, for the sample grown at $1.3 \mathrm{~Pa}$ oxygen pressure, there is extensive $\mathrm{Zn}$ diffusion into the sapphire substrate with the depth of $\sim 100 \mathrm{~nm}$ after the $900{ }^{\circ} \mathrm{C}$ annealing. The $\mathrm{Al}$ diffusion depth is similar to that found in the sample grown without oxygen, i.e., equal to $\sim 50 \mathrm{~nm}$. It is unclear why the sample grown with oxygen has more extensive $\mathrm{Zn}$ out-diffusion from the $\mathrm{ZnO}$ film, and further study is needed.

Hydrogen has been attributed to be the residual shallow donor associated with the n-type conduction in undoped $\mathrm{ZnO}^{28}$ It would be worthwhile to compare the thermal evolution of the H-concentrations and the electron concentrations to understand the carrier conduction in the present samples. For the as-grown samples, the sample grown with oxygen has higher $\mathrm{H}$-concentration but lower electron

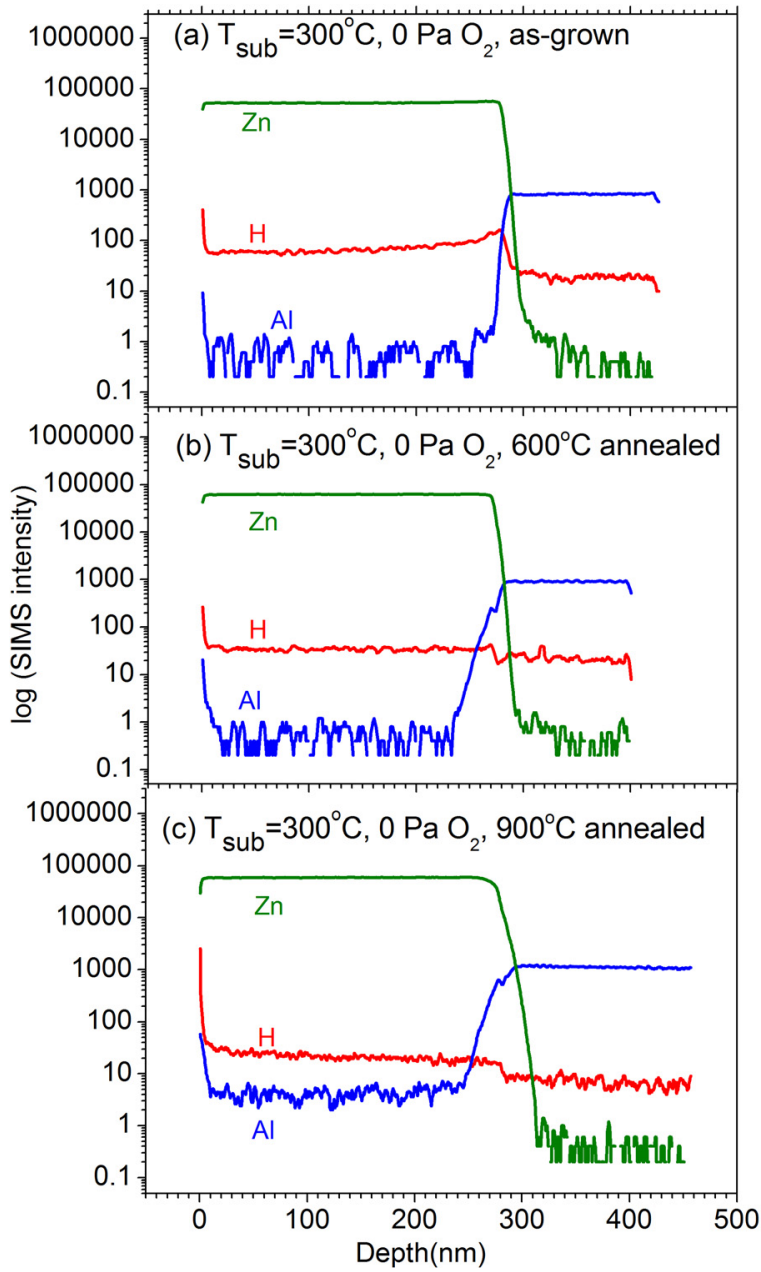

FIG. 6. The SIMS depth profiles of $\mathrm{H}, \mathrm{Zn}$, and $\mathrm{Al}$ of the (a) as-grown; (b) $600{ }^{\circ} \mathrm{C}$ annealed; and (c) $900^{\circ} \mathrm{C}$ annealed samples grown with oxygen pressure of $1.3 \mathrm{~Pa}$.

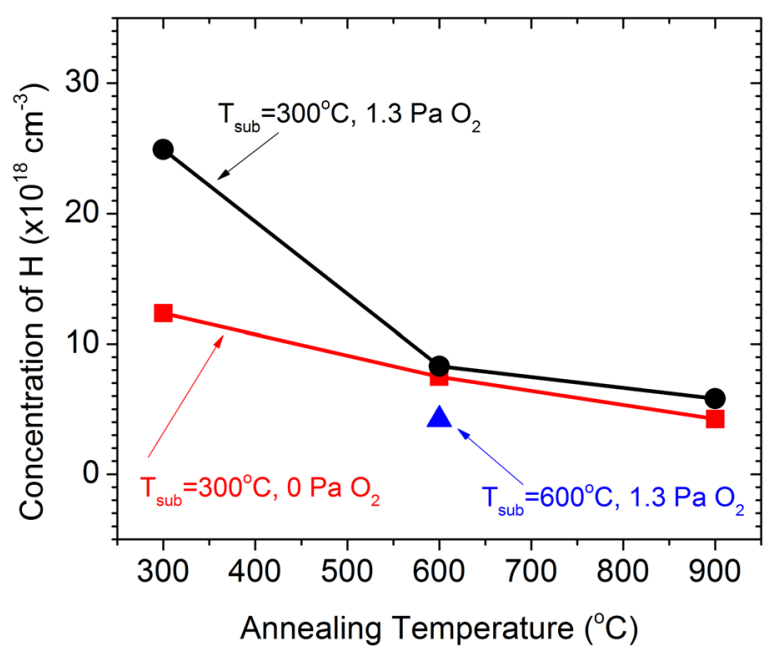

FIG. 7. The hydrogen concentration as a function of the annealing temperature for the samples grown with oxygen pressures of $0 \mathrm{~Pa}$ and $1.3 \mathrm{~Pa}$ at the substrate temperature of $300^{\circ} \mathrm{C}$. The hydrogen concentration of the asgrown sample grown with $1.3 \mathrm{~Pa}$ oxygen pressure and $600^{\circ} \mathrm{C}$ substrate temperature is also included. 
concentration than those grown without oxygen (Figures 4 and 7). The low electron concentration found in the $\mathrm{H}$ abundant sample grown in oxygen could be due to the inferior crystalline quality as revealed by the FWHM of the $\mathrm{ZnO}$ (002) XRD peak (Figure 3 ). The $\mathrm{H}$ concentrations for all the samples annealed at $600{ }^{\circ} \mathrm{C}$ lay within narrow range of $\sim 4-8$ $\times 10^{18} \mathrm{~cm}^{-3}$ (Figure 6). Irrespective of the initial growth conditions, the electron concentrations of all the samples annealed at $600{ }^{\circ} \mathrm{C}$ lays within the narrow range of $1-4$ $\times 10^{18} \mathrm{~cm}^{-3}$, which is close to that of the hydrogen concentration. It is plausible to suggest that hydrogen impurity is the important shallow donor responsible for the n-type conduction for the samples undergone the $600{ }^{\circ} \mathrm{C}$ annealing. Comparing the $\mathrm{H}$ concentration and electron concentration (Figures 4 and 7), the slight increase of electron concentration after the $900{ }^{\circ} \mathrm{C}$ annealing is not related to the hydrogen impurity.

Figure 8 shows the Raman spectra of the $\mathrm{ZnO}$ samples grown without oxygen undergone the $600{ }^{\circ} \mathrm{C}$ and $900{ }^{\circ} \mathrm{C}$ annealing in the Raman shift range of $490 \mathrm{~cm}^{-1}$ to $610 \mathrm{~cm}^{-1}$. Raman peaks of $584 \mathrm{~cm}^{-1}$ and $560 \mathrm{~cm}^{-1}$ have, respectively, been associated to the intrinsic defects of $V_{O}$ and $\mathrm{Zn}_{\mathrm{i}} \cdot{ }^{22-26}$ The broad Raman peak as seen in the $600{ }^{\circ} \mathrm{C}$ annealed sample (Figure 8) could be well fitted with the two intrinsic defect related peaks $\left(560 \mathrm{~cm}^{-1}\right.$ and $\left.584 \mathrm{~cm}^{-1}\right)$ in addition with the sapphire substrate related peak $\left(579 \mathrm{~cm}^{-1}\right)$. The resultant fitted curve and the corresponding components' curves are shown in Figure 8. For the Raman spectrum of the $900^{\circ} \mathrm{C}$ annealed sample as shown in Figure 8, thermal removal of the two intrinsic defect related peaks are clearly observed, and only the sapphire related peak remains. It would be interesting to investigate the stoichiometry dependence of these defect related Raman peaks. The intensities of

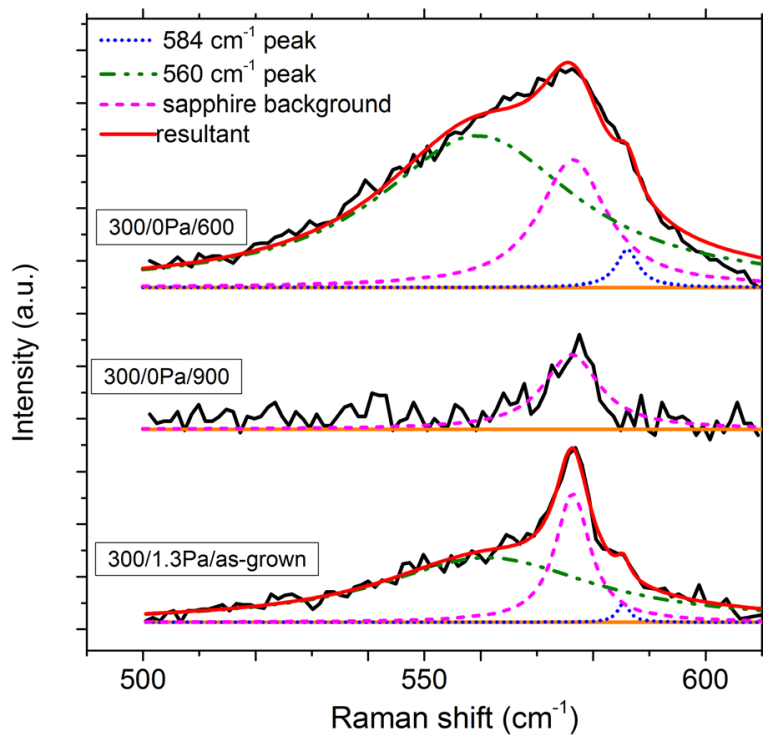

FIG. 8. The Raman spectra of the $\mathrm{ZnO}$ samples grown with (a) no oxygen and $\mathrm{T}_{\text {anneal }}=600^{\circ} \mathrm{C}$; (b) no oxygen and $\mathrm{T}_{\text {anneal }}=900^{\circ} \mathrm{C}$; and (c) oxygen pressure of $1.3 \mathrm{~Pa}$ and as-grown. The $560 \mathrm{~cm}^{-1}, 584 \mathrm{~cm}^{-1}$ and the sapphire peak are clearly observed in (a). By comparing (a) and (b), $900^{\circ} \mathrm{C}$ annealing has the effect of removing the $560 \mathrm{~cm}^{-1}$ and $584 \mathrm{~cm}^{-1}$ peaks. It is also noticed from (c) that $560 \mathrm{~cm}^{-1}$ and $584 \mathrm{~cm}^{-1}$ are suppressed by the presence of the oxygen.
TABLE I. The intensities of the two Raman peaks $560 \mathrm{~cm}^{-1}$ and $584 \mathrm{~cm}^{-1}$ for the as-grown samples grown at different oxygen pressure. The substrate temperature during growth is $300^{\circ} \mathrm{C}$.

\begin{tabular}{lcc}
\hline \hline & \multicolumn{2}{c}{ Intensities of Raman peaks } \\
\cline { 2 - 3 } Oxygen pressure during growth & $560 \mathrm{~cm}^{-1}$ & $584 \mathrm{~cm}^{-1}$ \\
\hline $0 \mathrm{~Pa}$ & $\sim 4000$ & $\sim 500$ \\
$1.3 \mathrm{~Pa}$ & 270 & 3 \\
$5 \mathrm{~Pa}$ & 186 & 0 \\
\hline \hline
\end{tabular}

the two Raman peaks of the as-grown samples grown with $\mathrm{PO}_{2}=0 \mathrm{~Pa}, 1.3 \mathrm{~Pa}$, and $5 \mathrm{~Pa}$ are tabulated in Table I.

Figure 9 summarizes the intensities of the two defect related peaks against the annealing temperature for the samples grown without oxygen. The annealing temperatures of the intrinsic defects associated with the $560 \mathrm{~cm}^{-1}$ and $580 \mathrm{~cm}^{-1}$ Raman peaks are $750-900^{\circ} \mathrm{C}$ and $600-750^{\circ} \mathrm{C}$. Table I clearly demonstrates that the $584 \mathrm{~cm}^{-1}$ peak intensity dramatically drops by orders of 100 and 10000 if the growing environment changes from no oxygen to $1.5 \mathrm{~Pa}$ and $5 \mathrm{~Pa}$ oxygen, respectively. For the intrinsic defect associated with the $560 \mathrm{~cm}^{-1}$ Raman peak, its intensity is less sensitive to the oxygen environment during growth. Its intensity is reduced by about 15 times and 30 times while the growing environment changes from no oxygen to $1.5 \mathrm{~Pa}$ and $5 \mathrm{~Pa}$ oxygen, respectively. It can be summarized that growing in oxygen environment would suppress the two intrinsic defect related $560 \mathrm{~cm}^{-1}$ and $584 \mathrm{~cm}^{-1}$ Raman peaks.

The assignment of the $560 \mathrm{~cm}^{-1}$ and $584 \mathrm{~cm}^{-1}$, respectively, to $\mathrm{Zn}_{\mathrm{i}}$ and $\mathrm{V}_{\mathrm{O}}$ as in the previous literatures such as Refs. 22-26 is compatible with the oxygen deficient nature as observed in the present study. $\mathrm{V}_{\mathrm{O}}$ is generally believed to have the U-negative property and has the energy state at $\varepsilon(0 /$ $2+)=0.4-0.8 \mathrm{eV}$ below the conduction band. The Fermi levels calculated from the electron concentration for the present samples are all well above the $\varepsilon(0 / 2+)$ of $\mathrm{V}_{\mathrm{O}}$, and thus the $\mathrm{V}_{\mathrm{O}}$ in the present samples should possess a zero charge state. Janotti and Van de Walle ${ }^{4}$ have obtained the theoretical value of $2.36 \mathrm{eV}$ for the migration barrier of neutral $\mathrm{V}_{\mathrm{O}}{ }^{0}$. This

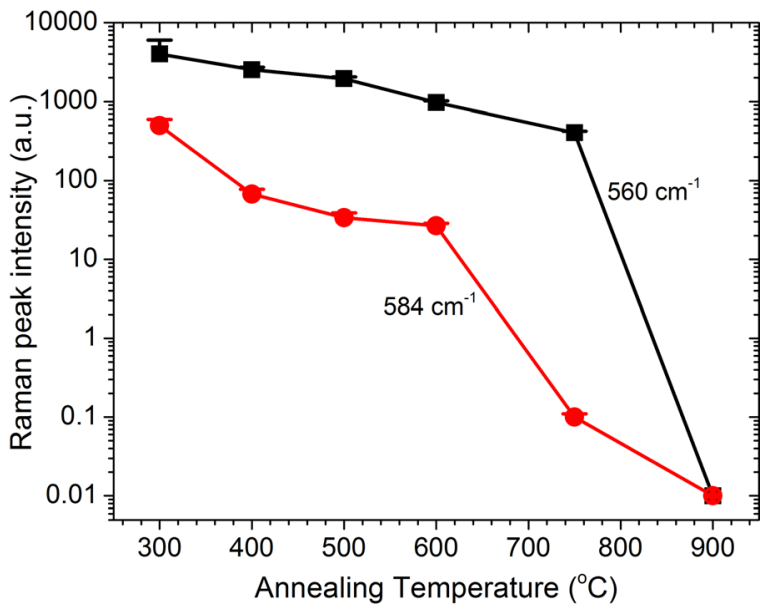

FIG. 9. The intensities of the $560 \mathrm{~cm}^{-1}$ and $584 \mathrm{~cm}^{-1}$ Raman peaks as a function of the annealing temperature. The Raman peak intensity is in $\log$ scale. The samples are grown with no oxygen. 
corresponds to the annealing temperature of $909 \mathrm{~K}$, which agrees well with the annealing temperature of the defect associated with the present $584 \mathrm{~cm}^{-1}$ Raman peak. The $584 \mathrm{~cm}^{-1}$ Raman peaks is thus attributed to the $V_{O}$. For the case of $Z_{i}$, theoretical calculation yields the migration barrier of $0.57 \mathrm{eV},{ }^{4}$ which corresponds to the annealing temperature of 219 K. Optically detected magnetic resonance (ODMR) study also shows that the $\mathrm{Zn}_{\mathrm{i}}$ anneals out at $170 \mathrm{~K}{ }^{29}$ In the present study, the $560 \mathrm{~cm}^{-1}$ anneals at temperature of $900^{\circ} \mathrm{C}$, even higher than that of $\mathrm{V}_{\mathrm{O}}$. The assignment of the $560 \mathrm{~cm}^{-1}$ Raman peak to $\mathrm{Zn}_{\mathrm{i}}$ is thus highly suspicious.

For $\mathrm{ZnO}$ materials, PAS technique is selectively sensitive to the Zn-vacancy related defects. To understand the thermal evolution of the $\mathrm{V}_{\mathrm{Zn}}$-related defects in the $\mathrm{ZnO}$ samples, PAS study was performed on the samples grown with the oxygen pressures of $0 \mathrm{~Pa}$ and $5 \mathrm{~Pa}$, and their $\mathrm{S}-\mathrm{W}$ plots were shown in Figure 10. For the presence of a single type of vacancy defect, the measured resultant S-parameter is the weighted sum of the contributions from the bulk state and the defect state, i.e., $S=(1-\eta) S_{b}+\eta S_{d}{ }^{30}$ where $\eta$ is the fraction of the positron annihilating at the defect state, $S_{b}$ and $S_{d}$ are the characteristic $S$-parameters of the bulk state and the defect state, respectively. Similar relation holds for the $W$-parameter, ${ }^{30} W=(1-\eta) W_{b}+\eta W_{d}$. Combining the two equations yields $S-S_{b}=R\left(W-W_{b}\right)$. This implies in the presence of the single type of positron trapping defect, plotting $S$-parameter against the $W$-parameter would yield a straight line with the slope of $R . R$ is the characterized $R$-parameter and is a fingerprint of the defect. To normalize against the $S_{b}$ and $W_{b}$, the normalized $R_{\text {normal }}$ is given by $R_{\text {normal }}=\left(W_{b} / S_{b}\right) R$.

For the samples grown without oxygen, the $S$ - $W$ data points of the as-grown, $400{ }^{\circ} \mathrm{C}, 500{ }^{\circ} \mathrm{C}$, and $600^{\circ} \mathrm{C}$ annealed samples lay on a straight line in the $S-W$ plot, implying single type of Zn-vacancy related defect (VZn-1) exists in these samples. For the samples grown at $5 \mathrm{~Pa}$ oxygen pressure, the data points lay on another straight line in the S-W plot,

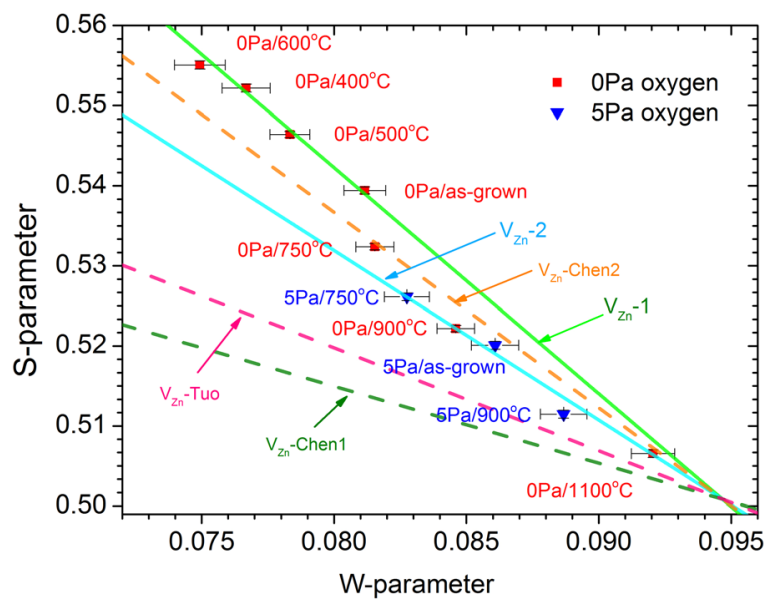

FIG. 10. The S-E parameter plot of the $\mathrm{ZnO}$ samples grown with no oxygen (color in red) and $5 \mathrm{~Pa}$ oxygen pressure (color in blue). Sample having the same single type of defect would have the S-E data falling on the same straight line. The S-E straight lines corresponding to VZn-1 and VZn-2 are shown. The S-E straight lines for the $\mathrm{Zn}$-vacancy related defects as found in Tuomisto et al. ${ }^{8,9}$ (VZn-Tuo) and Chen et al ${ }^{10}$ (VZn-Chen1 and $\mathrm{VZn-Chen2)} \mathrm{are} \mathrm{also} \mathrm{included} \mathrm{for} \mathrm{reference.}$ implying that another type of Zn-vacancy related defect (VZn-2) exists in these samples. It is noticed that the samples grown without oxygen annealed at $900^{\circ} \mathrm{C}$ and $1100{ }^{\circ} \mathrm{C}$ also lie on the VZn-2 straight line. The two straight lines intersects at $S_{b}=0.5008$ and $W_{b}=0.09467$, which are the characteristic $\mathrm{S}$ and $\mathrm{W}$ parameters of the defect free $\mathrm{ZnO}$ bulk state, respectively.

The whole picture is that VZn-1 exists in the as-grown sample grown without oxygen. At annealing temperature $\leq 600{ }^{\circ} \mathrm{C}, \mathrm{VZn}-1$ is the only detected Zn-vacancy related defect in the samples. Annealing the samples at $900^{\circ} \mathrm{C}$ would initiate the conversion of $\mathrm{VZn}-1$ to another $\mathrm{Zn}$ vacancy related defect VZn-2 with a different microstructure. For the samples grown with $5 \mathrm{~Pa}$ oxygen, VZn-2 exists in the as-grown sample as well as the post-growth annealed ones. VZn-2 persists after the $1100{ }^{\circ} \mathrm{C}$ annealing.

In the previous paragraph, it has been stated that the slight increase of electron concentrations after the $900{ }^{\circ} \mathrm{C}$ annealing was not associated with the hydrogen impurity. As the $\mathrm{S}-\mathrm{W}$ data points of $0 \mathrm{~Pa} / 750{ }^{\circ} \mathrm{C}, 0 \mathrm{~Pa} / 900{ }^{\circ} \mathrm{C}, 5 \mathrm{~Pa} / 750{ }^{\circ} \mathrm{C}$, and $5 \mathrm{~Pa} / 900^{\circ} \mathrm{C}$ lay on the straight line of $\mathrm{VZn}-2$ implying the type of Zn-vacancy is the same, their S-parameters are the direct indication of the corresponding Zn-vacancy concentration. From Figure 10, the Zn-vacancy concentrations of the samples grown with and without oxygen drop after the $900{ }^{\circ} \mathrm{C}$ annealing. The thermal reduction of the $\mathrm{Zn}$-vacancy compensating center could be the cause for the slight increase of electron concentration after the $900{ }^{\circ} \mathrm{C}$ annealing.

Tuomisto et al. ${ }^{8,9}$ studied the seeded vapor phase grown $\mathrm{ZnO}$ bulk using the PAS technique and showed that $\mathrm{Zn}$ vacancy is the dominant acceptor in the as-grown and the electron irradiated samples (denoted by VZn-Tuo). The $\mathrm{V}_{\mathrm{Zn}}$ has the characteristic fingerprint that the normalized $\mathrm{S}$ parameter and $\mathrm{W}$-parameter of $\mathrm{S}_{\mathrm{D}}=1.039$ and $\mathrm{W}_{\mathrm{D}}=0.87$, and the positron lifetime of $230 \mathrm{ps}$ as compared to the bulk value of 170 ps. Oxygen-vacancy and a negatively charged ion are also identified in the modeled analysis of the PAS data, although their characteristic positron lifetime is close to that of the bulk. The negative ion is attributed to Ointerstitial or oxygen antisite. The VZn-Tuo has two annealing stages namely at $400 \mathrm{~K}$ and $550 \mathrm{~K}$, indicating that it is part of two different defect complexes. The oxygen vacancy anneals out together with the second annealing stage of $\mathrm{V}_{\mathrm{Zn}}$, i.e., $550 \mathrm{~K}$. Chen et al. ${ }^{10}$ carried out PAS study on electron irradiated hydrothermal grown $\mathrm{ZnO}$ bulk samples. Znvacancy related defect (denoted by VZn-Chen1) was induced by electron irradiation. Post-irradiation annealing at temperature below $\sim 400^{\circ} \mathrm{C}$ would reduce the concentration of VZnChen1. Annealing at $400{ }^{\circ} \mathrm{C}$ would create another kind of Zn-vacancy related defect (VZn-Chen2). Combining with the Raman scattering result which reveal the presence of oxygen vacancy, the formation of the secondary $\mathrm{V}_{\mathrm{Zn}}$-related defect (VZn-Chen2) and the simultaneous annealing out of the $V_{O}$ Raman signal is attributed to the displacement of the $\mathrm{Zn}$ atom neighboring the $\mathrm{V}_{\mathrm{O}}$ to the $\mathrm{V}_{\mathrm{O}}$ and thus the formation of the $\mathrm{V}_{\mathrm{Zn}} \mathrm{Zn}_{\mathrm{O}}$, i.e., $\mathrm{V}_{\mathrm{O}}+\mathrm{Zn}_{\mathrm{Zn}} \rightarrow \mathrm{V}_{\mathrm{Zn}} \mathrm{Zn}_{\mathrm{O}}$. In a subsequent study of comparing the experimental Doppler broadening of annihilation radiation (DBAR) spectrum with the theoretical one calculated by the local density 
approximation model, Chen et al. ${ }^{11}$ confirmed that the VZnChen2 defect is the $\mathrm{V}_{\mathrm{Zn}} \mathrm{Zn}_{\mathrm{O}}$ defect complex.

The characteristic S-W straight lines corresponding to VZn-Tuo, VZn-Chen1, and VZn-Chen2 are included in the present S-W plot (Figure 10) for the purpose of comparison. It is noticed that the VZn-1 and VZn-2 observed in the present study are not the Zn-vacancy related defects observed in the vapor phase grown nor the hydrothermal grown single crystal bulk samples. However, the S-W data point of the $750^{\circ} \mathrm{C}$ annealed sample grown without oxygen (denoted by VZn-3) lays on the S-W characteristic line of VZn-Chen2, which is attributed to $\mathrm{V}_{\mathrm{Zn}} \mathrm{Zn}_{\mathrm{O}}$. It coincides with the annealing temperature of the $584 \mathrm{~cm}^{-1} \mathrm{~V}_{\mathrm{O}}$ related Raman line. The same coincidence was also found in the case of the creation of $\mathrm{V}_{\mathrm{Zn}} \mathrm{Zn}_{\mathrm{O}}$ and the disappearance of $\mathrm{V}_{\mathrm{O}}$ in the hydrothermal grown $\mathrm{ZnO}$ bulk though at the lower temperature of $400^{\circ} \mathrm{C}$, which was ascribed to the $\mathrm{V}_{\mathrm{O}}+\mathrm{Zn}_{\mathrm{Zn}} \rightarrow \mathrm{V}_{\mathrm{Zn}} \mathrm{Zn}_{\mathrm{O}}$ process. $^{10,11}$ The $\mathrm{S}-\mathrm{W}$ data point (i.e., $\mathrm{VZn}-3$ ) is thus attributed to $\mathrm{V}_{\mathrm{Zn}} \mathrm{Zn}_{\mathrm{O}}$.

It is noticed from Figure 10 that even at temperature as high as $1100^{\circ} \mathrm{C}$, the Zn-vacancy in the PLD grown film has not yet been completely annealed out. This temperature is high as compared to the previously reported annealing temperature of the $\mathrm{Zn}$-vacancy related defects in bulk single crystals, for examples $550 \mathrm{~K}$ (i.e., $\sim 280^{\circ} \mathrm{C}$ ) in vapor phase grown, ${ }^{9}$ and $400^{\circ} \mathrm{C}$ in hydrothermal grown. ${ }^{10,31}$ The extra thermal persistence of $\mathrm{Zn}$-vacancy related defect in the present $\mathrm{ZnO}$ films could be due to the thermally fragile $\mathrm{ZnO} /$ sapphire interface. Thermal induced inter-diffusions of $\mathrm{Al}$ and $\mathrm{Zn}$ were observed in the SIMS measurement of the present study, as well as in other literature. ${ }^{32}$ The $\mathrm{Zn}$ out-diffusion would inevitably create $\mathrm{Zn}$-vacancy related defects in the $\mathrm{ZnO}$ film and this could explain the presence of Zn-vacancy related defect in the present samples annealed at temperature as high as $1100^{\circ} \mathrm{C}$. The issue of the thermally fragile $\mathrm{ZnO} /$ sapphire interface is important as the thermally induced Zn-vacancy would influence the electrical property of the film, like compensating the p-type conductivity in the p-doping attempt.

From Figures 5 and 6, it is observed that the $900{ }^{\circ} \mathrm{C}$ annealing induced $\mathrm{Zn}$ out-diffusion from the $\mathrm{ZnO}$ film for the sample grown in oxygen is much more extensive than that grown without oxygen. It is thus expected that the $\mathrm{Zn}$ vacancy related defects created by the $900^{\circ} \mathrm{C}$ annealing in the sample grown in oxygen is more than that grown without oxygen. From the S-W plot in Figure 10, the S-parameter of the $900{ }^{\circ} \mathrm{C}$ annealed samples grown in oxygen is smaller than that grown without oxygen, implying that the $\mathrm{Zn}$ vacancy concentration in the $900^{\circ} \mathrm{C}$ annealed sample grown with oxygen is less than that grown without oxygen, which is contrary to the expectation. It seems to suggest that $\mathrm{Zn}$ vacancy annealing out in the O-rich sample is more effective. Nevertheless, the exact reason is unknown and requires further investigation.

\section{CONCLUSION}

Thermal evolution of defects in PLD grown $\mathrm{ZnO}$ samples was studied. Extensive out-diffusion of $\mathrm{Zn}$ into the sapphire substrate $(\sim 100 \mathrm{~nm})$ was found at the $\mathrm{ZnO} /$ sapphire interface of the $900^{\circ} \mathrm{C}$ annealed sample grown with oxygen, but the $\mathrm{Zn}$-out-diffusion is limited to $\sim 50 \mathrm{~nm}$ for the sample grown without oxygen. The results of the annealing and stoichiometric studies of the $584 \mathrm{~cm}^{-1}$ Raman line are compatible with the assignment of this line to oxygen vacancy. However, the result of the annealing study of the $560 \mathrm{~cm}^{-1}$ shows that it has higher thermal stability than that expected for $\mathrm{Zn}_{\mathrm{i}}$, and thus the previous literature assignment of this line to $Z_{n}$ is suspicious. $Z n$-vacancy related defects $V Z n-1$, $\mathrm{VZn}-2$, and $\mathrm{VZn}-3$ having different microstructure are identified in the PLD grown samples. Annealing or growing the sample in oxygen would favor the formation of VZn-2. VZn2 persisted after the $1100^{\circ} \mathrm{C}$ annealing.

\section{ACKNOWLEDGMENTS}

This work was supported by the Research Grant Council, HKSAR under the GRF Project No. 703612P.

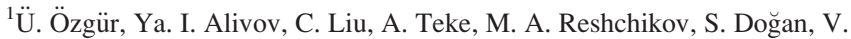
Avrutin, S.-J. Cho, and H. Morkoç, J. Appl. Phys. 98, 041301 (2005).

${ }^{2}$ D. C. Look, Phys. Status Solidi B 241, 624 (2004).

${ }^{3}$ V. Avrutin, D. J. Silversmith, and H. Morkoç, Proc. IEEE 98, 1269 (2010).

${ }^{4}$ A. Janotti and C. G. Van de Walle, Phys. Rev. B 76, 165202 (2007).

${ }^{5}$ A. Janotti and C. G. Van de Walle, Rep. Prog. Phys. 72, 126501 (2009).

${ }^{6}$ F. Oba, M. Choi, A. Togo, and I. Tanaka, Sci. Technol. Adv. Mater. 12, 034302 (2011).

${ }^{7}$ M. D. McCluskey and S. J. Jokeia, J. Appl. Phys. 106, 071101 (2009).

${ }^{8}$ F. Tuomisto, V. Ranki, K. Saarinen, and D. C. Look, Phys. Rev. Lett. 91, 205502 (2003).

${ }^{9}$ F. Tuomisto, K. Saarinen, D. C. Look, and G. C. Farlow, Phys. Rev. B 72, 085206 (2005).

${ }^{10}$ Z. Q. Chen, S. J. Wang, M. Maekawa, A. Kawasuso, H. Naramoto, X. L. Yuan, and T. Sekiguchi, Phys. Rev. B 75, 245206 (2007).

${ }^{11}$ Z. Q. Chen, K. Betsuyaku, and A. Kawasuso, Phys. Rev. B 77, 113204 (2008).

${ }^{12}$ G. Brauer, W. Anwand, D. Grambole, J. Grenzer, W. Skorupa, J. Č́ížek, J. Kuriplach, I. Procházka, C. C. Ling, C. K. So, D. Schulz, and D. Klimm, Phys. Rev. B 79, 115212 (2009).

${ }^{13}$ J. C. Fan, C. Y. Zhu, S. Fung, C. D. Beling, Y. C. Zhong, K. S. Wong, Z. Xie, G. Brauer, W. Anwand, W. Skorupa, C. K. To, B. Yang, C. D. Beling, and C. C. Ling, J. Appl. Phys. 106, 073709 (2009).

${ }^{14}$ C. K. To, B. Yang, S. C. Su, C. C. Ling, C. D. Beling, and S. Fung, J. Appl. Phys. 110, 113521 (2011).

${ }^{15}$ F. A. Selim, M. H. Weber, D. Solodovnikov, and K. G. Lynn, Phys. Rev. Lett. 99, 085502 (2007).

${ }^{16}$ R. Diggle, Phys. Rev. Lett. 23, 579 (1969).

${ }^{17}$ B. Guo, Z. R. Qiu, and K. S. Wong, Appl. Phys. Lett. 82, 2290 (2003).

${ }^{18}$ K. Vanheusden, C. H. Seager, W. L. Warren, D. R. Tallant, and J. A. Volgt, Appl. Phys. Lett. 68, 403 (1996).

${ }^{19}$ X. L. Wu et al., Appl. Phys. Lett. 78, 2285 (2001).

${ }^{20}$ B. X. Lin, Z. X. Fu, and Y. B. Jia, Appl. Phys. Lett. 79, 943 (2001).

${ }^{21}$ N. O. Korsunska, L. V. Borkovska, B. M. Bulakh, L. Yu Khomenkova, V. I. Kushnirenko, and I. V. Markevich, J. Lumin. 102-103, 733 (2003).

${ }^{22}$ X. Q. Wei, B. Y. Man, M. Liu, C. S. Xue, H. Z. Zhuang, and C. Yang, Physica B 388, 145 (2007).

${ }^{23}$ H. J. Fan, R. Scholz, F. M. Kolb, M. Zacharias, U. Gösele, F. Heyroth, C. Eiwenschmidt, T. Hempel, and J. Christen, Appl. Phys. A 79, 1895 (2004).

${ }^{24}$ C. Li, J. Lv, S. Yao, J. Hu, and Z. Liang, Nuclear Instrum. Methods Phys. Res. B 295, 11 (2013).

${ }^{25}$ D. Messerschmidt, K. Bratz, W. Gnehr, H. Romanus, J. Eberhardt, S. Nicolay, and C. Ballif, J. Appl. Phys. 115, 094902 (2014).

${ }^{26}$ X. Xue, L. Liu, Z. Wang, and Y. Wu, J. Appl. Phys. 115, 033902 (2014).

${ }^{27}$ J. F. Ziegler, J. P. Biersack, and U. Littmark, The Stopping and Range of Ions in Solids (Pergamon, New York, 1985).

${ }^{28}$ C. G. Van de Walle, Phys. Rev. Lett. 85, 1012 (2000).

${ }^{29}$ L. S. Vlasenki and G. D. Watkins, Phys. Rev. B 72, 035203 (2005).

${ }^{30}$ F. Tuomisto and I. Makkonen, Rev. Mod. Phys. 85, 1583 (2013).

${ }^{31}$ L. W. Lu, C. K. So, C. Y. Zhu, C. J. Li, S. Fung, G. Brauer, W. Anwand, W. Skorupa, and C. C. Ling, Semicond. Sci. Technol. 23, 095028 (2008).

${ }^{32}$ R. S. Wang, Q. L. Gu, C. C. Ling, and H. C. Ong, Appl. Phys. Lett. 92, 042105 (2008). 